\title{
Aislamiento de Cryptococcus neoformans y Salmonella spp. en excretas de palomas domésticas (Columba livia) de la Basílica Catedral de Lima y Convento de San Francisco Lima, Perú
}

Isolation of Cryptococcus neoformans and Salmonella spp. in excreta of domestic pigeons (Columba livia) of the Cathedral Basilica of Lima and Lima

Convent of San Francisco, Peru

Ornela Chávez Inagaki ${ }^{1}$, Angélica Terashima Iwashita ${ }^{2}$, Marco Canales Ramos ${ }^{2}$, Beatriz Bustamante, Víctor Meza Contreras ${ }^{4}$, Néstor Falcón Pérez ${ }^{1}$

\section{RESUMEN}

Las palomas urbanas (Columba livia) son portadoras de diversos agentes patógenos de importancia zoonótica para el hombre, entre ellas Salmonella spp. y Cryptococcus neoformans; los problemas no son para los que manipulan las palomas, sino quienes puedan inhalar esporas infectantes presentes en las heces. El objetivo del estudio fue evaluar la presencia de Salmonella spp. y C. neoformans en excretas de palomas de la Basílica Catedral de Lima y el Convento de San Francisco de Asís de Lima. Se realizó un estudio observacional. Se tomaron muestras en fachadas, torres, escaleras altas, techos, campanario y balcones. Se recolectaron 47 muestras secas para C. neoformans y 40 muestras frescas para Salmonella. Las muestras secas se sembraron en medios de cultivos Sabouraud y Niger Seed. Las muestras frescas se sembraron en medio pre-enriquecido. A las colonias sospechosas de ser C. neoformans se les realizó examen directo con tinta china y prueba de asimilación de urea. Las colonias positivas en ambas pruebas, se cultivaron en agar L-Canavanina-Glicina-azul de Bromotimol (CGB) para diferenciar C. neoformans y C. gatti. Se confirmó la identificación de C. neoformans mediante el método API 20C AUX. Se encontró que todas las muestras frescas fueron negativas a Salmonella spp. y en 9/47 muestras secas se aisló C. neoformans. En conclusión, la presencia de muestras positivas a $C$. neoformans debe alertar a las autoridades correspondientes para evaluar e implementar estrategias de control de la población de palomas.

PALABRAS CLAVE: Cryptococcus neoformans, Salmonella spp., zoonosis, palomas.

\section{SUMMARY}

Background: Urban pigeons (Columba livia) can be carriers of various zoonotic pathogens of medical importance to humans, including Salmonella spp. and Cryptococcus neoformans, the problems are not for those who manipulate pigeons, but those who can inhale infecting spores present in the feces. The objective was to evaluate the presence of Salmonella spp. and C. neoformans in pigeon droppings recovered from the Basilica Cathedral and San Francisco

Facultad de Medicina Veterinaria y Zootecnia, Universidad Peruana Cayetano Heredia. Lima Perú,

Laboratorio de Parasitología, Instituto de Medicina Tropical Alexander von Humboldt de la Universidad Peruana Cayetano Heredia. Lima Perú,

Laboratorio de Micología Clínica, Instituto de Medicina Tropical Alexander von Humboldt de la Universidad Peruana Cayetano Heredia. Lima,

Perú,

4 Universidad Nacional Agraria La Molina, Lima Perú, 
Convent, both in Lima. This was an observational study. Samples were taken from facades, towers, high stairs, rooves, the bell tower and balcony. Forty-seven dry samples were collected for determination of the presence of C. neoformans and 40 fresh fecal samples for Salmonella. Dry samples were plated on Sabouraud and Niger Seed culture media. Fresh samples were plated on pre-enriched medium. Suspected colonies of being C. neoformans were given direct examination with India ink and urea assimilation test. Positive colonies in both tests, were grown on agar L-canavanine glycine bromothymol blue (CGB) agar to differentiate C. neoformans and C. ghatti. C. neoformans identification was confirmed using API 20C AUX method. All fresh samples were negative for Salmonella spp. and in 9/47 dry samples, C. neoformans was isolated. In conclusion, the presence of positive samples for C. neoformans should alert the authorities to evaluate and implement strategies to control the pigeon population.

KEY WORDS: Cryptococcus neoformans, Salmonella spp, zoonosis, pigeons.

\section{INTRODUCCIÓN}

La paloma doméstica (Columba livia) puede causar problemas sanitarios actuando como reservorio natural de microorganismos, pudiendo transmitir a los humanos más de treinta enfermedades infecciosas; siendo de mayor importancia para la salud pública la salmonelosis y la criptococosis (González-Acuña et al., 2007).

El género Salmonella presenta una epidemiología muy compleja, asociada a la contaminación ambiental y a la existencia de infinidad de reservorios (Rabsch, Hargis y Tsolis, 2000). La forma subclínica es la más frecuente e importante, debido al comensalismo entre los diferentes serotipos de Salmonella y el ave, sin que se produzca la patología. El principal problema es que al localizarse en el tracto digestivo de las aves (Pinheiro, de Oliveira, y Berchieri, 2001), puede transmitirse a través de las heces a otros animales así como a sus productos (carne y huevos) y a través de éstas, llegar al ser humano constituyendo una de las principales causas de toxiinfección alimentaria (Dunkley et al., 2009).

Las bacterias del género Salmonella causan en el hombre una gastroenteritis aguda con cefalalgia, dolores abdominales súbitos, diarrea, náuseas, fiebre y vómitos. Aunque la morbilidad por salmonelosis es elevada, la mortalidad es baja, excepto en niños de corta edad, ancianos e inmunodeprimidos (Caffer y Terragno, 2001).

En cuanto a la criptococcosis, Emmons (1955) estableció el rol de la paloma como portadora del $C$. neoformans aislándola en sus excretas. Sin embargo, la criptococosis no es una enfermedad que se presenta en forma clínica en las palomas (Tudor, 1991), debido a su alta temperatura corporal $\left(41-43^{\circ} \mathrm{C}\right)$ y por su flora intestinal. Este hongo también se puede localizar en el suelo, estiércol y polvo contaminado con heces de aves y, se ha descrito que puede afectar tanto al hombre como a los animales domésticos y silvestres. La adquisición en el ser humano se manifiesta por vía respiratoria, provocando generalmente una neumonía granulomatosa y meningitis (Montesinos, Salas y Ramírez, 2003). Tras el descubrimiento de Emmons (1955), investigadores de casi todo el mundo han demostrado que las deposiciones de paloma son importantes reservorios de C. neoformans. Staib (1963) indicó que las excretas de palomas favorecen el crecimiento del hongo por el alto contenido que tienen de nitrógeno, creatinina, ácido úrico, guanina, xantina y a una elevada concentración de sales. Sin embargo, para Currie, Frundlich y Casadevall (1994), el suelo y las excretas pueden ser ambientes hostiles para $C$. neoformans cuando están expuestos a la radiación solar, temperaturas extremas, condiciones anaeróbicas, baja humedad y extrema acidez. También mencionan que las altas concentraciones de amoníaco en excretas frescas inhiben el crecimiento de la levadura.

Por estos motivos, algunos de ellos consideran que el hongo no suele aislarse en deyecciones recientes, pero sí en las acumuladas y secas existentes en palomares, aleros de edificios, áticos o balcones de casas abandonadas donde duermen las palomas (Kielstein, Bocklisch, Hotzel, Schmalreck y Otto, 2000; Mattsson, Haemig y Olsen, 1999), y pocas veces se aísla de suelos orgánicamente enriquecidos (Emmons, 1955). Esta teoría coincide con el estudio de Arredondo (2000), en el cual obtuvo resultados positivos a $C$. neoformans en heces secas de palomas con altas concentraciones de levaduras, al ser es un ambiente desfavorable para el crecimiento de la mayoría de los otros microorganismos.

Se ha estimado que la permanencia de la levadura en deyecciones de palomas a la sombra, húmedas $o$ desecadas, pueden ser por más de dos años. 
Para Rosario, Acosta y Colom (2008), la exposición directa al sol al parecer no destruye la levadura, debido a que las especies patógenas de Cryptococcus producen pigmentos melanoides que les permiten utilizar las radiaciones como energía metabólica. Sin embargo, otros estudios no muestran diferencias significativas en la frecuencia de aislamiento entre los excrementos secos y los frescos (Castañón-Olivares et al., 2000). Una característica microbiológica de importancia para el diagnóstico es la actividad ureásica que presentan los aislados (Fernández et al., 1998).

El pronóstico de la meningoencefalitis criptococósica no tratada es fatal (Mitchell y Perfect, 1995). Si el paciente tiene títulos altos de antígeno criptococósico antes del inicio de la terapia, es más probable que no responda al tratamiento o que fallezca antes que éste termine (Diamond y Bennet, 1974). La criptococosis meníngea ha sido la tercera infección más frecuente del SNC en los pacientes con SIDA, luego de la encefalopatía provocada por el HIV y las encefalitis por Toxoplasma gondii. Aproximadamente del 6 al 10\% de los pacientes con SIDA desarrollarán meningitis criptocócica y cerca del $40 \%$ de los casos será el primer evento definitorio de SIDA (Powderly, 1993).

La presencia de palomas urbanas se encuentra en gran cantidad en los alrededores de la Basílica Catedral de Lima y el Convento de la Iglesia de San Francisco, donde concurren una gran cantidad de personas con fines religiosos y turísticos, por lo que se hace apremiante esclarecer el rol de estas aves como potenciales fuentes de infección de criptococosis y salmonelosis en los humanos. Por lo tanto, el objetivo de esta investigación es evaluar la presencia de Salmonella spp. y C. neoformans por aislamiento microbiológico, en las excretas de palomas que proceden de las zonas adyacentes a la Basílica Catedral de Lima y del Convento de San Francisco.

\section{MATERIAL Y MÉTODOS}

El diseño del estudio fue observacional, de corte transversal y descriptivo.

El estudio se realizó en la Basílica Catedral de Lima y el Convento de San Francisco de Asís ubicados en el centro histórico de la ciudad de Lima, Perú. La población objetivo fueron las palomas que se encontraron en estos lugares y, solo se trabajó con sus deyecciones. Para el estudio de C. neoformans, las muestras de heces secas se recolectaron del interior de ambos sitios y se obtuvieron de aquellos espacios de difícil acceso a las personas, donde no había limpieza. Para hallar Salmonella, se utilizaron heces frescas del exterior del Convento de San Francisco.

El diagnóstico de las muestras se realizó siguiendo los protocolos que se resumen a continuación:

a. Aislamiento de C. neoformans: Se tomaron $10 \mathrm{~g}$ de heces secas de cada muestra, se procesaron para sembrarlas en medios de cultivo Sabouraud (detección de hongos) y Agar semilla de girasol que contenían cloranfenicol y difenil. Las placas se incubaron entre los 28 y $30^{\circ} \mathrm{C}$ durante 14 días para el crecimiento de colonias. Posteriormente, las colonias sospechosas se colocaron en láminas y se colorearon con una gota de tinta china para el examen directo con microscopio. Las colonias positivas de los aislados se colocaron en tubos con urea. Un cambio de coloración del medio de naranja a violeta indicó que la muestra era positiva (asimilación de urea) a Cryptococcus. Luego se realizó el cultivo de las mismas en agar L-Canavanina-Glicina-azul de Bromotimol (CGB) para diferenciar entre $C$. neoformans o $C$. gatti. Finalmente, se evaluaron por API 20C AUX (Catalogue Analytique: API 20C AUX) para su validación.

b. Aislamiento de Salmonella spp: Se tomaron muestras frescas con hisopos estériles y se recolectaron en tubos con medio de conservación (Cary Blair) para transportarlas al laboratorio. Estas fueron obtenidas sobre papel que se colocó en el piso para evitar que las heces se contaminen. Las muestras se conservaron en un contenedor térmico tipo caja con refrigerantes a una temperatura aproximada de $4^{\circ} \mathrm{C}$ para ser trasladadas al Laboratorio de Microbiología, en un tiempo aproximado de dos horas post recolección de las muestras. En el laboratorio, las muestras se almacenaron en refrigeración hasta su procesamiento, el cual se basó en cuatro etapas sucesivas:

- $\quad$ Pre enriquecimiento en medio no selectivo

- Enriquecimiento en medios selectivos líquidos

Aislamiento e identificación

- Confirmación: En caso las muestras hubiesen resultado positivas, se confirmaría con los medios de ensayos bioquímicos y serológicos apropiados y se utilizaría alguna prueba de confirmación final como API AUX o PCR para diagnóstico definitivo (Cano, 2006). 
Para hallar Salmonella spp., solo se tomaron deyecciones frescas de palomas inmediatamente después de ser expulsadas por las aves.

Los resultados fueron resumidos en tablas de frecuencia, mostrando la frecuencia absoluta y relativa de muestras positivas a las diferentes pruebas de laboratorio empleadas. Para determinar la diferencia entre las proporciones de muestras positivas según lugar de muestreo se utilizó la prueba exacta de Fisher.

\section{RESULTADOS}

Se recolectaron 40 muestras frescas para el aislamiento de Salmonella spp. y 47 muestras secas para el aislamiento de C. neoformans. El detalle de los lugares y puntos de muestreo para cada caso se encuentra en la tabla 1.

No se encontró ninguna muestra positiva al aislamiento de Salmonella spp.

De las 47 muestras secas, 43 resultaron positivas a crecimiento de hongos $(91,5 \%)$ y 40 resultaron positivas a crecimiento de colonias sospechosas a $C$. neoformans (85,0\%) en medio de Agar semilla de girasol. La distribución de los resultados según lugar de muestreo se observa en la tabla 2.

Con respecto a los hongos, a todas las 40 muestras sospechosas a $C$. neoformans se les realizó la prueba de tinta china, 34 muestras resultaron positivas $(85,0 \%)$. De éstas, solo se obtuvieron 11 cepas purificadas a partir de los cultivos en agar Agar semilla de girasol de ambos puntos del muestreo, debido al crecimiento de colonias de otros tipos de hongos que impidieron un aislamiento individual. De las 11 cepas, 9 resultaron positivas a las pruebas de confirmación (Urea positiva, CGB y API), a $C$. neoformans $(81,8 \%$ ) y las a 2 cepas restantes no se lograron identificar la especie. El detalle de la distribución de los resultados positivos según el lugar del muestreo se observa en la tabla 2.

\section{DISCUSIÓN}

El aumento de la población de palomas en nuestra ciudad, se debe principalmente a factores antropogénicos como la costumbre de alimentar a estos animales, ofrecerles cobijo y descuido en el recojo de basura que son utilizados como fuente de alimentación por estas aves (Rosario et al., 2008).

La gran cantidad de palomas que proliferan en el Convento de San Francisco de Asís y la que existió en la Basílica Catedral de Lima ha permitido la

Tabla 1. Distribución de las muestras de heces secas de paloma (Columba livia) tomadas para el aislamiento de Cryptococcus neoformans y heces frescas para el aislamiento de Salmonella spp., según el lugar y zona de muestreo. Lima - 2011.

\begin{tabular}{|c|c|c|c|}
\hline Lugar de muestreo & Zona de muestreo & No. de muestras & Total muestras por lugar \\
\hline \multicolumn{4}{|l|}{ HECES SECAS } \\
\hline \multirow{4}{*}{$\begin{array}{c}\text { Convento San } \\
\text { Francisco de Asís }\end{array}$} & Balcón de la biblioteca del museo & 5 & \multirow{4}{*}{20} \\
\hline & Campanario torreón derecho & 5 & \\
\hline & Campanario torreón izquierdo & 5 & \\
\hline & Escalera de la parte alta de la torre & 5 & \\
\hline \multirow{7}{*}{$\begin{array}{c}\text { Basílica Catedral de } \\
\text { Lima }\end{array}$} & Fachada Catedral (Calle Carabaya) & 2 & \multirow{7}{*}{27} \\
\hline & Torre del bautisterio (nivel más alto) & 5 & \\
\hline & Techo del cuarto de maquinarias & 3 & \\
\hline & Escaleras de madera internas de la torre & 5 & \\
\hline & Balcón de la torre del bautisterio & 4 & \\
\hline & Torre del bautisterio (nivel inferior) & 5 & \\
\hline & Techo del sagrario & 3 & \\
\hline \multicolumn{4}{|l|}{ HECES FRESCAS } \\
\hline & Escaleras de ingreso a la Iglesia & 10 & \multirow{4}{*}{40} \\
\hline Convento de San & Zona de la puerta lateral de la iglesia & 10 & \\
\hline \multirow[t]{2}{*}{ Francisco de Asís } & Alrededor de la puerta principal del Museo & 10 & \\
\hline & Alrededor de la pileta. & 10 & \\
\hline
\end{tabular}


Tabla 2. Resultados de crecimiento de colonias sospechosas a C. neoformans a partir de muestras secas de heces de paloma (Columba livia) cultivadas en medios Sabouraud y Agar semilla de girasol, y resultados positivos de las diversas pruebas confirmatorias realizadas para asilar C. neoformans para cada lugar de muestreo. Lima - 2011

Tipo de Pruebas

\begin{tabular}{|c|c|c|c|c|c|c|c|c|c|c|c|c|}
\hline \multirow{2}{*}{$\begin{array}{l}\text { Lugar de } \\
\text { muestreo }\end{array}$} & \multirow{2}{*}{$\begin{array}{l}\text { Total de } \\
\text { muestras }\end{array}$} & \multicolumn{2}{|c|}{ Sabouraud $(+)$} & \multicolumn{2}{|c|}{$\begin{array}{l}\text { Agar semilla de } \\
\text { girasol (+) }\end{array}$} & \multirow{2}{*}{$\begin{array}{l}\text { No. de } \\
\text { cepas* }\end{array}$} & \multicolumn{2}{|c|}{ Urea (+) } & \multicolumn{2}{|c|}{ CGB } & \multicolumn{2}{|c|}{ API } \\
\hline & & $\mathbf{n}$ & $\%$ & n. & $\%$ & & $\mathbf{n}$ & $\%$ & No. & $\%$ & No. & $\%$ \\
\hline $\begin{array}{l}\text { Convento San } \\
\text { Francisco de Asís }\end{array}$ & 20 & 20 & $100.0^{\mathrm{a}}$ & 4 & 75 & 4 & 3 & 75 & 3 & 75 & 3 & 75 \\
\hline $\begin{array}{c}\text { Basílica Catedral } \\
\text { de Lima }\end{array}$ & 27 & 23 & $85,2^{\mathrm{a}}$ & 7 & 85,7 & 7 & 6 & 85,7 & 6 & 85,7 & 6 & 85,7 \\
\hline TOTAL & 47 & 43 & 91.5 & 11 & 81,8 & 11 & 9 & 81,8 & 9 & 81,8 & 9 & 81,8 \\
\hline
\end{tabular}

acumulación de cantidades de heces secas y restos de palomas en sus alrededores, favoreciendo el deterioro del hábitat y el bienestar urbano, constituyendo reservorios de importantes agentes zoonóticos como hongos, bacterias y parásitos que pueden contaminar los alimentos, los suministros de agua y el ambiente. Por lo tanto, es un problema importante para la salud pública.

De estos lugares se recolectaron muestras de heces secas para hallar C. neoformans. En el caso de las heces frescas solamente se recolectaron del exterior del Convento de San Francisco, debido a que en la Catedral de Lima existe actualmente un mayor control de higiene y normas que restringen la alimentación de las aves.

El tipo de muestra es un factor determinante para aislar los microorganismos en estudio. En la investigación se decidió tomar muestras de heces secas para determinar la presencia de $C$. neoformans siguiendo los resultados de los estudios de Kielstein (Kielstein et al., 2000; Mattsson et al., 1999).

Sin embargo, existe discrepancia al respecto. Castañón et al. (2000) mencionan que no existe diferencia entre heces secas y frescas para el desarrollo de C. neoformans. En el estudio se decidió recolectar heces secas encontradas en las sombras y alejadas de los lugares donde no se realiza limpieza en los techos. También se tomaron muestras de heces secas encontradas en balcones y fachadas donde si llegaban los rayos solares ultravioletas, a fin de determinar si este factor intervenía en la probabilidad de aislar a $C$. neoformans, tal como lo mencionan Caicedo, Álvarez,
Llanos y Molina (1996) en su estudio en Colombia, que los rayos ultravioletas ejercen una acción letal sobre las levaduras, limitando su crecimiento. Los resultados de este estudio, fueron muestras positivas a C. neoformans en ambos casos, demostrando que las heces de palomas expuestas a los rayos ultravioleta del sol (muestras obtenidas en los balcones y fachadas) y las encontradas bajo techo y sombra (escaleras altas, campanarios y torre del bautisterio) son medios propicios para el desarrollo del hongo.

La totalidad de las muestras frescas resultaron negativas a Salmonella spp., esto no quiere decir que las palomas no sean portadoras de esta bacteria. Una serie de factores se pueden asociar a ello, entre éstas, la calidad de la conservación, transporte, almacenamiento o la cantidad de muestra. Los procesos posteriores siguieron los protocolos establecidos y de existir muestras falsas negativas, no ha sido posible identificar los puntos en los que la calidad de la muestra se haya visto alterada.

Una de las limitaciones del trabajo fue no haber usado los métodos de biología molecular para la detección de Salmonella spp., lo cual hubiese permitido revelar su presencia cuando esta se encontrase en pequeñas cantidades de inóculo, pero los costos para la detección molecular de Salmonella spp. son elevados en comparación con los métodos tradicionales.

De las 47 muestras sembradas en agar Sabourod y Niger Seed, solo en 9 de ellas $(19 \%)$ se aisló $C$. neoformans, debido a que en la mayoría de placas crecían abundantes hongos de diferentes tipos que dificultaban su aislamiento. 
En ambos lugares de estudio se realizan reuniones propias de las actividades parroquiales, donde puede haber condiciones favorables que expongan a los visitantes a infecciones con microorganismos zoonóticos de transmisión aerógena.

La determinación del C. neoformans fue importante para diferenciar aquellos que son zoonóticos de los que son propios de plantas, como es el caso de C. gatti (Canelo et al., 1999).

Según Nielsen, De Obaldia y Heitman (2007), el C. neoformans sólo se encuentra en heces de animales portadores, debido a que el microorganismo no encuentra condiciones favorables fuera de ella. Mencionan que en el suelo existe limitación de nutrientes al no obtener crecimiento de $C$. neoformans sobre los cultivos de muestra de suelos contaminados con heces en contraste a lo obtenido en este estudio, directamente de la muestra de heces, confirmando que las heces de palomas son ambientes propicios para el crecimiento del hongo.

La presencia de $C$. neoformans en las heces secas del Convento de San Francisco y en la Basílica Catedral de Lima confirma las condiciones necesarias para el desarrollo del hongo, coincidiendo con estudios de Caicedo et al. (1996), donde se describe un aislamiento del hongo en excretas secas de palomas de un 49,6\%, considerando que existe una relación positiva entre la presencia de C. neoformans y el acúmulo de heces, tanto como una alta densidad de palomas.

Debido a la importancia sobre la salud de las personas, especialmente de algunos grupos vulnerables (personas con problemas de inmunidad), es necesario tomar medidas que eviten la acumulación de heces de palomas en la ciudad y, realizar un control de la población de palomas a fin de evitar la exposición del hombre a microorganismos que utilizan a las heces como reservorio.

Se requiere de futuras investigaciones orientadas a determinar con mayor exactitud los efectos de la acumulación de heces, ventilación de los ambientes, así como la exposición a la radiación solar sobre la supervivencia del hongo C. neoformans.

Agradecimientos: A Rosario Velando, Susy Aranibar y Azucena Grigoletto del Laboratorio de Micología del IMT “Alexander von Humboldt", UPCH por cooperar en el proceso de las muestras para C. neoformans; al Sr. Matzumura por autorizar el ingreso a la Basílica
Catedral de Lima; al Fraile Chambi por autorizar el ingreso al Convento San Francisco de Lima; a la Blga. Maribel Riveros Ramírez del IMT “Alexander von Humboldt", UPCH por su contribución con el procesamiento de las muestras para Salmonella; a la Sra. Olivia Inagaki por revisar la redacción del artículo y a la Fotógrafa Harumi Tanaka por tomar las fotos durante la recolección de muestras.

Esta investigación fue financiada parcialmente por el Consejo Nacional de Ciencia y Tecnología del Perú (CONCYTEC), gracias al otorgamiento de una subvención PROCYT N $\mathrm{N}^{\circ}$ 330-2010. Además, el Laboratorio de Micología Clínica del Instituto de Medicina Tropical (IMT) Alexander von Humboldt subvencionó complementariamente el trabajo de laboratorio y de gabinete.

El estudio contó con la aprobación del Comité Institucional de Ética de la Universidad Peruana Cayetano Heredia.

\section{Correspondencia:}

Ornela Chávez Inagaki

Urb. Asincoop, Calle Julio Rodavero 1 G 23. Lima, Perú

Celular: 51959227191

Correo electrónico: ornela.chavez@upch.pe

\section{REFERENCIAS BIBLIOGRÁFICAS}

1. Arredondo, C. (2006). Cryptococcus neoformans en heces de palomas recolectadas en lugares públicos de la ciudad de santiago, Chile. Trabajo de investigación para optar al título de médico veterinario. Universidad Iberoamericana de Ciencias y Tecnología. Santiago de Chile.

2. Caffer, M. \& Terragno, R. (2001). Manual de procedimientos para la caracterización de salmonella. Buenos Aires, Argentina: Ministerio de Salud.

3. Caicedo, L.D., Álvarez, M.I., Llanos, C.E., \& Molina, D. (1996). Cryptococcus neoformans en excretas de palomas del perímetro urbano de cali. Colombia Médica, 27(3-4), 106-109.

4. Canelo C., Navarro A., Guevara M., Urcia F., Zurita S., \& Casquero J. (1999). Determinación de la variedad de cepas de Cryptococcus neoformans aisladas de pacientes con SIDA. Revista Peruana De Medicina Experimental y Salud Publica, 16(1-2), 44-47.

5. Cano S. (2006). Métodos de análisis microbiológico, 
normas ISO, UNE. Burgos: Analiza Calidad ed.

6. Castañón-Olivares, L.R., Arreguín-Espinosa, R., Ruiz-Palacios y Santos, G. \& López-Martínez, R. (2000). Frequency of Cryptococcus species and varieties in México and their comparison with some Latin American countries. Revista Latinoamericana de Microbiología, 42, 35-40.

7. Currie B., Frundlich I., \& Casadevall A. (1994). Restriction fragment length polymorphism analysis of Cryptococcus neoformans isolates from environmental (pigeon excreta) and clinical sources in New York city. Journal of Clinical Microbiology, 32(5), $1188-1191$.

8. Diamond, R.D., \& Bennet, J. E. (1974). Prognostic factors in cryptococcal meningitis: Study of 111 cases. Ann Intern Med, 80, 176-181.

9. Dunkley, K.D., Callaway, T.R., Chalova, V.I., McReynolds, J.L., Hume, M. E., \& Dunkley, C.S., (2009). Foodborne Salmonella ecology in the avian gastrointestinal tract. Anaerobe, 15(1), 26-35. doi:https://doi.org/10.1016/j.anaerobe.2008.05.007

10.Emmons C. W. (1955). Saprophytic sources of Cryptococcus neoformans associated with the pigeon (Columba livia). American Journal of Epidemiology, 62(3), 227-232.

11. Fernández, C. M., Martínez, G., Illnait, M. T., Perurena, M., \& González, M.(1998). Identificación de Cryptococcus neoformans var. neoformans en aislamientos clínicos cubanos. Revista Cubana De Medicina Tropical, 50(2), 167-169.

12. González-Acuña, D., Silva G. F., Moreno S. L., Cerda L. F., Donoso E S., Cabello, C. \& López M. J. (2007). Detección de algunos agentes zoonóticos en la paloma doméstica (Columba livia) en la ciudad de Chillán, Chile. Revista Chilena De Infectología, 24(3), 199-203.

13. Kielstein, P., Bocklisch, H., Hotzel, H., Schmalreck, A., \& Otto, B. (2000). Evidence of Cryptococcus neoformans in domestic and sports pigeons in Thyringia. Mycoses, 43, 23-28.
14. Mattsson, R., Haemig, P.D., \& Olsen, B. (1999). Feral pigeons as carriers of Cryptococcus laurentii, Cryptococcus uniguttulatus and Debaryomyces hansenii. Med Mycol, 37, 367-9.

15. Mitchell, T. G, \& Perfect, J. R. (1995). Cryptococcosis in the era of AIDS--100 years after the discovery of Cryptococcus neoformans. Clinical Microbiology Reviews, 8(4), 515-548.

16. Montesinos, L.I., Salas G., \& Ramírez, J. (2003). Curso pre congreso necropsias, toma y envío de muestras de bovinos. Ciudad de México: Departamento de Patología Facultad de Medicina Veterinaria y Zootecnia. Universidad Nacional Autónoma de México.

17. Nielsen, K., De Obaldia A.L., \& Heitman, J. (2007). Cryptococcus neoformans mates on pigeon guano: Implications for the realized ecological niche and globalization. Eukaryot Cell, 6(6), 949959.

18.Pinheiro L.A., de Oliveira G.H., \& Berchieri A. (2001). Experimental Salmonella enteric or var pullorum infection in two commercial varieties of Laying hens. Avian Pathology, 30, 129-133.

19. Powderly, W. (1993). Meningitis criptocócica y Sida. Clinical infectious diseases, 17, 837-842.

20. Rabsch, W., Hargis, B.M., \& Tsolis, R.M. (2000). Competitive exclusion of Salmonella enteritidis by Salmonella gallinarum in poultry. Emerging Infectious Diseases, 6(5), 443-448.

21. Rosario I., Acosta B., \& Colom F. (2008). La paloma y otras aves como reservorio de Cryptococcus spp. Revista Iberoamericana de Micología, 25(1), S13-S18.

22. Staib, F. (1963). New concepts in the occurrence and identification of Cryptococcus neoformans. Mycopathol Mycology Appl, 19, 143-145.

23. Tudor, D. (1991). Pigeon health and diseases. Iowa: Iowa State University Press. 